\title{
Research on the Influence of the Characteristics of the Board of Directors of Listed Companies on the Growth of the Company
}

\author{
Gao Ruirui ${ }^{1}$ \\ ${ }^{1}$ Scool of Economics and Management, Beijing Jiaotong University, Beijing, China
}

\begin{abstract}
The board characteristics are an important factor affecting the growth of the company. This paper selects the data of A-share listed companies in the Shanghai and Shenzhen Stock Exchanges during the fiveyear period from 2014 to 2019, and analyzes whether the board characteristics will affect the growth of the company from a dynamic perspective. The research found that: (1) the scale of the board of a listed company has an inverted U-shaped relationship with the company's growth; (2) the proportion of independent directors has a positive correlation with the company's growth; (3) the director's salary has a positive correlation with the company's growth.
\end{abstract}

\section{1.introduction}

The development of the company depends on good corporate governance. If corporate governance can make effective decisions and can supervise the management to ensure efficient operation of the company, then it will correspondingly increase the market value of the company, and the growth of the company can be improved accordingly ${ }^{[1]}$. The level of company growth can determine whether a listed company has development prospects and whether it is operating well. Listed companies that lack growth potential cannot achieve their own development and growth.

Growth ability is the current state of the company under the combined effect of internal and external factors. The governance mechanism becomes the center of the corporate governance structure. A reasonable board governance mechanism that strictly abides by the requirements in actual use according to regulations can enhance the company's value on the one hand, and promote the company's future development on the other hand ${ }^{[2]}$.

\section{Theoretical analysis and research hypothesis}

A larger board of directors can better perform the functions of the board of directors, thereby reducing the company's decision-making risks; however, more board members will cause inconvenience in communication and coordination among members. When the board of directors is small, on the one hand, it facilitates communication and coordination among directors, thereby promoting company development; on the other hand, the quality of meeting decisions may be low; at the same time, the smaller board of directors has a lower level of supervision, evaluation and control over the company's managers ${ }^{[3]}$. Based on the above analysis, this paper proposes the following research hypotheses 1 :

Hypothesis 1: There is an inverted U-shaped relationship between the scale of the board of directors of a listed company and the growth of the company.

Based on the principal-agent theory, the introduction of the independent director system can improve the independence of the board of directors, strengthen the supervision of operating managers ${ }^{[4]}$. In addition, the independent directors introduced by the company are generally experts in a certain field or aspect, which can improve the quality of board resolutions to a certain extent ${ }^{[5]}$. Based on the above analysis, this paper proposes the following research hypotheses 2 :

Hypothesis 2: There is a positive correlation between the proportion of independent directors of listed companies and the growth of the company.

Agency theory believes that in order to better align the interests of directors and shareholders, it is necessary to establish a variety of market and restriction mechanisms to encourage and supervise directors. Motivation theory believes that when the material rewards of the employees of a company are improved, their spiritually recognized needs will be met, and they will be more active in the work $^{[6]}$. Based on the above analysis, this paper proposes the following research hypotheses 3 :

Hypothesis 3: There is a positive correlation between the compensation of directors of listed companies and the growth of the company.

\section{Research design}

\subsection{Sample selection and data sources}

The sample of this article is selected from my country's 
Shanghai and Shenzhen A-share listed companies from 2015 to 2019. In terms of screening data, we follow the following standards: (1) Excluding listed companies in the financial industry; (2) exclude ST and *ST companies that appeared in any year during this period; (3) eliminate companies with abnormal data and other missing financial data. The above sample company data are from the CSMAR database, and statistical software Stata 16.0 is used for statistical analysis of the data.

\subsection{Variable selection}

The explained variable: Tobin's Q value TQ: market value/total assets. Explaining variables: Board size variable num: the total number of board members; board structure variable inde: the ratio of independent directors; incentive level of directors lnpay: namely directors' salary. Control variables: The company size variable lnsize: the natural logarithm of the total assets; equity concentration variable share: the shareholding ratio of the largest shareholder; the annual dummy variable Year; industry dummy variable Industry. They are shown in Table 1.

Table1 Variable definition

\begin{tabular}{cc}
\hline symbols & Variable definition \\
$\boldsymbol{T} \boldsymbol{Q}$ & Market value/total asset \\
inum & Total number of board members \\
inde & Number of independent directors/ total number of board members \\
Insize & Ln(total remuneration of the top three directors) \\
share & Ln(total asset) \\
$\sum$ year & The largest shareholder's shareholding ratio \\
$\sum$ industry & Year dummy variable \\
\hline
\end{tabular}

\subsection{Model construction}

Based on the relevant research hypotheses and variable design proposed in the previous normative analysis, this paper establishes the equation as follows:

$$
\begin{aligned}
& \mathrm{TQ}=\beta_{0}+\beta_{1} \text { num }+\beta_{2} \text { num }^{2}+\beta_{3} \text { inde }+ \\
& \beta_{4} \text { lnpay }+\beta_{5} \text { lnsize }+\beta_{6} \text { share }+\beta_{7} \text { year }+ \\
& \beta_{8} \text { industry }
\end{aligned}
$$

\section{Empirical results and analysis}

\subsection{Descriptive statistics}

Based on the data obtained from the above screening, we conducted a descriptive statistical analysis of the explanatory variables and the explained variables, as shown in Table 2.

It can be seen from the results in Table 2: First, in terms of the explained variables, the average value of Tobin's $Q$ value TQ, which is an indicator of corporate growth, is 2.164 , and the standard deviation is 2.107 , indicating that the selected sample company's growth during the fiveyear period from 2014 to 2019 The level varies greatly. Analyzing the reason, it may be that the operating conditions of listed companies in different industries are very different, which leads to gaps in their growth capabilities. Second, in terms of explanatory variables, the mean board size num is 8.47 and the standard deviation is 1.681 , indicating that there are indeed differences between the selected companies, which may be caused by the size of the sample companies and the different corporate governance cultures; independent directors The average value of the ratio inde is 0.377 , which meets the requirement of more than $1 / 3$ of the ratio of independent directors in the "Guiding Opinions on the Establishment of an Independent Director System in Listed Companies" issued by the my country Securities Regulatory Commission. The standard deviation is 0.0562 , which is a small difference; the logarithm of directors' salary The mean value of lnpay is 14.36 , the standard deviation is 0.759 , the difference is small.

Table 2 descriptive statistics

\begin{tabular}{lccccc}
\hline & $\mathrm{N}$ & mean & $\mathrm{sd}$ & $\min$ & $\max$ \\
\hline num1 & 13,613 & 8.470 & 1.681 & 3 & 20 \\
num2 & 13,613 & 74.57 & 30.90 & 9 & 400 \\
inde & 13,613 & 0.377 & 0.0562 & 0.200 & 0.800 \\
lnpay & 13,613 & 14.36 & 0.759 & 8.039 & 18.30 \\
lnsize & 13,613 & 22.31 & 1.306 & 18.29 & 28.52 \\
share & 13,613 & 33.77 & 14.54 & 0.290 & 89.99 \\
TQ & 13,613 & 2.164 & 2.017 & 0.694 & 86.50 \\
\hline
\end{tabular}




\subsection{The empirical results and analysis}

\begin{tabular}{cc} 
& Table3 regression result \\
\hline Variables & \\
num1 & $T Q$ \\
& $-0.172^{* * *}$ \\
num2 & $(-3.37)$ \\
& $0.009^{* * *}$ \\
inde & $(3.70)$ \\
& $1.418^{* * *}$ \\
lnpay & $(3.88)$ \\
& $0.102^{* * *}$ \\
lnsize & $(4.17)$ \\
share & $-0.586^{* * *}$ \\
& $(-20.63)$ \\
\end{tabular}

Perform regression analysis based on the model established above, as shown in Table 3. From the results in Table 3 , it can be seen that the adjusted $\mathrm{R}^{\wedge} 2$ of the model is 0.241 , indicating that the goodness of fit of the model is relatively good, and the selected variables can explain the company's growth to a certain extent. The F value is 69.36 and the $p$ value is 0.0000 , indicating that the model has passed the $F$ test. This series of indicators shows that the model constructed in this paper is reasonable, and the selected board characteristic variables have a certain degree of explanatory power for Tobin's Q value. The specific analysis is as follows: (1) Director scale variable num: The regression coefficient of the board scale variable is -0.172 , indicating that the board size is negatively correlated with company growth, that is, the expansion of the board scale is not conducive to company growth. Significant at the $1 \%$ level of significance indicates that it is highly statistically significant. The coefficient of the square of the board size is positive, but the value is small, but it is significant, indicating that the board size and the company's growth may show a quadratic curve correlation relationship that first rises and then declines, that is, H1 is established. (2) Proportion of independent directors: The regression coefficient of the variable inde of the independent director ratio is 1.418 , indicating that the ratio of independent directors is positively correlated with the company's growth, that is, the increase in the ratio of independent directors is conducive to the growth of the company. Significant at the $1 \%$ level of significance indicates that it is highly statistically significant. It shows that the proportion of independent directors is positively correlated with the company's growth, that is, $\mathrm{H} 2$ is established. (3) Director's salary: The regression coefficient of the natural logarithm of director's salary Inpay is 0.102 , indicating that the director's salary is positively correlated with the company's growth, that is, the increase of director's salary is beneficial to the company's growth. Significant at the $1 \%$ level of significance indicates that it is highly statistically significant. It shows that there is a positive correlation between director compensation and company growth, that is, H3 is established. Through the results of the regression analysis in the above table, we found that the selected control variables are basically related to the explained variables. Although the company's equity concentration variable is not significant, the company size variable is highly significant, indicating that these factors have an impact on the company's growth. With more important influence relations, it has a certain control effect on the regression results of the model.

\subsection{Robustness test}

The above-mentioned multiple regression analysis results initially reveal the relationship between the characteristics of the board of directors and the company's growth. In order to be cautious in the study, a robustness test is also required. In the robustness test, the company's growth indicators are replaced, and the company's growth rate of operating income is measured. Although the size of the board of directors failed the $t$ test, it cannot be said that it has nothing to do with the growth of the company. Its coefficient is consistent with the main test, which supports the important effect of the size of the board on the growth of the company to a certain extent. From the perspective of the proportion of independent directors, it is negatively correlated. This may be because independent directors are not familiar with the company's daily operation and management. Compared with the company's internal directors, there is a problem of information asymmetry, which is not conducive to the effective performance of independent directors' functions. It can be seen from the regression coefficient of directors' compensation that there is a positive correlation between directors' compensation and company growth, which is consistent with Hypothesis

\section{Conclusion}

(1) There is an inverted U-shaped relationship between the size of the board of directors and the company's growth. A larger board of directors is conducive to making higherquality decisions, but at the same time, more board members will cause inconvenience in communication and coordination among members; a smaller board of directors facilitates communication and coordination between directors, thereby promoting Company development; but at the same time, a small board of directors may result in low quality of meeting decisions, which is not conducive to the company's business development. (2) There is a positive correlation between the proportion of independent directors and the company's growth. The introduction of the independent director system can strengthen the independence of the board of directors, and at the same time, it is not easy to form insider control problems, thereby protecting the interests of small and medium shareholders and other stakeholders, improving internal governance problems, improving the company's operating performance, and promoting the healthy growth of the company. (3) There is a positive correlation between director compensation and company growth. When the material rewards of the employees of the company are improved, their spiritually recognized needs will be met, and they will be more active in the work they are engaged in, and the efficiency will be higher, which is conducive to 
the development of the company. To a certain extent, increasing the salary of directors can promote the growth of the company.

\section{References}

1. Du Xiaoguang, Dai Zeguang, Li Xin. Research on the Characteristics of Board of Directors and the Growth of Small and Medium-sized Enterprises from the Perspective of Equity Check [J]. CFA, 09,7376(2013).

2. Yang Fan, Yang Fengshuang. Management Characteristics, Institutional Investors and Company Growth [J]. Statistics and Decision, 36, 167170(2020).

3. Zhuo Min, Yao Qing. An Empirical Study on the Characteristics of Board of Directors and Company Growth [J]. Statistics and Decision, 24, 194-197 (2013).

4. Lipton, Lorsch. A Modest Proposal for Improved Corporate Governance [J]. Business Lawyer,48,5977(1992).

5. Yermack. Higher Market Valuation of Companies with a Small Board of Directors [J]. JFE,40,185438(1996).

6. Murphy, K.J. Stock - based Pay in New Economy Firms [J]. JAE, 01,129-147(2003). 